\title{
Pneumologia
}

\section{Cardiac sarcoidosis: Case report and review of the literature}

\author{
Cristina Manuela Tirziu ${ }^{1, *}$, Vlad-Cristian Zeca², Razvan Cristian Tirziu
}

${ }^{1}$ Clinical Emergency Hospital, Bucharest, Romania

${ }^{2}$ Emergency Institute for Cardiovascular Diseases "Prof. Dr. C. C. Iliescu", Bucharest, Romania

${ }^{3}$ Medical Diagnostic and Treatment Center "Acad. Stefan Milcu", Bucharest, Romania

Abstract

\section{English:}

Sarcoidosis is a rare inflammatory multisystem disease, frequently underdiagnosed and often clinically silent, with a negative prognosis on patient's survival should the cardiovascular system be involved. This occurs not only due to the direct involvement of the heart and blood vessels but also due to associated organ dysfunctions, most commonly pulmonary sarcoidosis. Cardiac sarcoidosis typically manifests as either conduction disturbances or, less commonly, as tachy- or bradyarrhythmia, sometimes even with signs and/or symptoms of heart failure. In this article, we present the case of a relatively young female patient with few significant comorbidities, who presented to the emergency department for palpitations with a high heart rate, which ultimately turned out to be caused by sustained ventricular tachycardia. The diagnostic steps undertaken thereafter reveal an underlying pulmonary sarcoidosis with cardiac involvement.

Keywords

\section{Sarcoidoza cardiaca: prezentare de caz si revizuire a literaturii}

Rezumat

\section{Romanian:}

Sarcoidoza este o boala inflamatorie multisistemica rara, adesea subdiagnosticata, frecvent paucisimptomatica, cu o importanta conotatie prognostica in cazul afectarii sistemului cardiovascular, atat prin afectare directa, cat si prin disfunctiile de organ asociate, cea mai frecvent asociata fiind cea pulmonara. In mod tipic sarcoidoza cardiaca se manifesta prin tulburari de conducere si, relativ mai rar, prin tahi- sau bradiaritmii cardiace, precum si fenomene de insuficienta cardiaca. In cele ce urmeaza, prezentam cazul unei paciente tinere, cu putine comorbiditati semnificative asociate, la care debutul clinic al sarcoidozei a fost doar prin palpitatii cu ritm rapid, ce tradeaza ulterior prezenta unei tahicardii ventriculara sustinute, lantul diagnostic urmand a releva prezenta unei sarcoidoze pulmonare cu afectare cardiaca.

Cuvinte-cheie

sarcoidoza cardiaca • tahicardie ventriculara • rezonanta magnetica cardiovasculara $\bullet$ biopsie ganglion limfatic $•$ corticoterapie

\section{Introduction}

Sarcoidosis is a systemic inflammatory disease characterised by the presence of noncaseating granulomata in the affected tissues. Although sarcoidosis can involve any organ system, lung involvement is observed in $>90 \%$ of cases. On the other hand, cardiac sarcoidosis is clinically evident in only around $5 \%$ of cases and is generally associated with systemic disease $(1,11)$. It is noteworthy that about $25 \%$ of patients with cardiac sarcoidosis do not have extracardiac manifestations of sarcoidosis (2).
Cardiac sarcoidosis most frequently presents as a variable degree of atrioventricular heart block. In almost one-third of cases, cardiac sarcoidosis may initially present as a tachyarrhythmia, atrial or ventricular in origin. Apart from the important arrhythmic burden, $20 \%$ of patients with cardiac sarcoidosis may also present with heart failure, which phenotypically may manifest as dilative, hypertrophic, restrictive or arrhythmogenic cardiomyopathy $(1,3,4)$. The

${ }^{*}$ Corresponding author: Cristina Manuela Tirziu

E-mail: tirziuc@yahoo.com

ว Open Access. (C) 2021 Tirziu et al., published by Sciendo

(c) BY-NC-ND This work is licensed under the Creative Commons Attribution-NonCommercial-NoDerivs 4.0 License. 
long-term prognosis of patients with cardiac sarcoidosis is worse than for those without cardiac involvement. Left ventricular ejection fraction is the most important prognostic factor in clinically manifest cardiac sarcoidosis $(1,3)$.

\section{Case report}

A 52-year-old woman, with a history of arterial hypertension, was admitted to the hospital with a 3-day history of newonset regular palpitations accompanied by diaphoresis and dizziness. The palpitations were self-limited, not correlated with effort. She denies having had any syncope, thoracic pain, dyspnoea or other complaints.

On physical examination, the patient was overweight (with a BMI of 29), blood pressure of $155 / 85 \mathrm{mmHg}$, heart rate (HR) $90 \mathrm{bpm}$, spontaneous peripheral oxygen saturation of $97 \%$, with no other abnormal findings. Electrocardiogram (EKG) showed sinus tachycardia at $100 \mathrm{bpm}$ and slight $(<0.5 \mathrm{~mm})$ ST segment elevation and negative T waves in DIII and aVF. EKG monitoring in the emergency room (ER) (approximately 3 h) revealed no rhythm disturbances. Laboratory exams were unremarkable apart from mild hyperglycemia and hypercholesterolemia, with normal cardiac troponins.
The chest X-ray on admission showed only enlarged pulmonary hila. A screening transthoracic cardiac ultrasound showed normal left ventricular ejection fraction without any regional wall motion abnormalities and apparently no significant valvular disease.

The consulting cardiologist considered it a non-urgent cardiological case and recommended a $24 \mathrm{~h}$ Holter monitoring in the outpatient sitting. Taking into consideration the fact that the patient had cardiovascular risk factors and the complaints were compatible with that of a heart rhythm disturbance, the decision was taken to admit the patient in the Internal Medicine ward for further investigation.

On the 2nd day of admission, a Holter EKG recording was begun and at the beginning of which the patient stated her palpitations had recurred and a sustained ventricular tachycardia (ventricular tachycardia) at $170 \mathrm{bpm}$ was revealed. A surface EKG showed ventricular tachycardia with a right bundle branch like morphology and significant left axis deviation $\left(-60^{\circ}\right)$ (Figure 1). Prompt amiodarone infusion was started and the patient was immediately transferred to the cardiac intensive care unit $(\mathrm{CICU})$.

When admitted in the $\mathrm{CICU}$, the patient was hemodynamically stable, with EKG monitoring showing normal sinus rhythm with HR 90 bpm. Repeated echocardiography showed

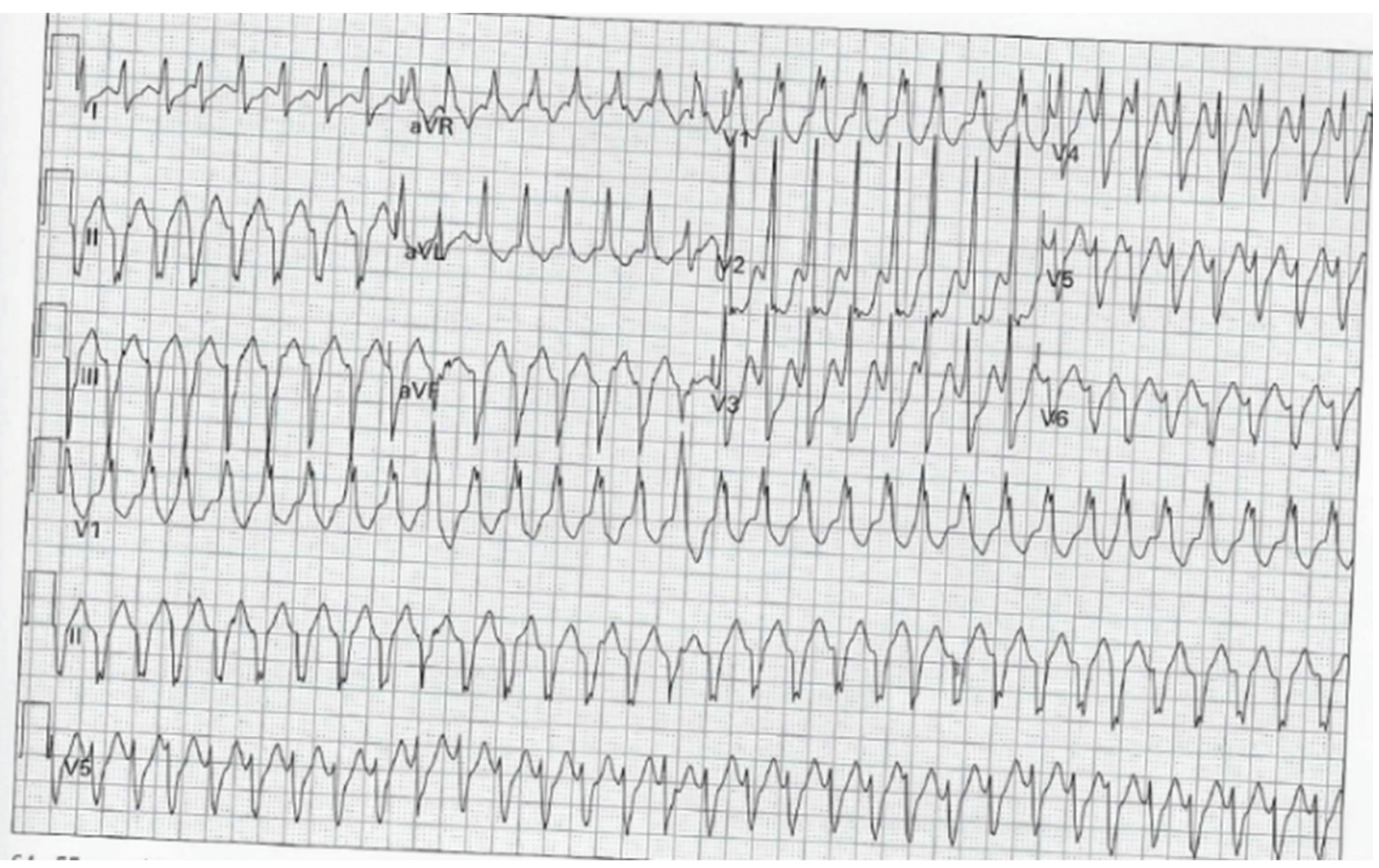

Figure 1. EKG demonstrating ventricular tachycardia with a right bundle branch block morphology and left axis deviation, HR 170 bpm. HR, heart rate. 
only grade I diastolic dysfunction. Thyroid function, serum electrolytes, NTpro-BNP and cardiac troponins were normal. Serum angiotensin converting-enzyme levels could not be determined because of the economic and logistic constraints of an emergency hospital. It is also noteworthy that the patient had normal pulmonary function tests, without any evidence of restrictive or obstructive pulmonary dysfunction.

On the 3rd day of admission, the EKG monitor shows monomorphic wide QRS tachycardia with HR 210 bpm, similar to the ventricular tachycardia episodes described on the Holter EKG. The coronary angiography shows no hemodynamically significant lesions of the epicardial coronary arteries. The electrophysiological study was performed: with electrode at the apex of the interventricular septum, a hemodynamically stable, sustained, monomorphic ventricular tachycardia was induced.

Amiodarone treatment was continued. An ablation procedure for the treatment of ventricular tachycardia was also considered but deemed non-urgent at that moment.
The cardiac magnetic resonance showed borderline low left ventricular volumes with preserved left ventricular function (left ventricular ejection fraction 67\%), normal right ventricular size and function and a limited area of scar tissue/fibrosis at the basal portion of the inferolateral segment of the left ventricle (LV) at the level of the mid-myocardium with late gadolinium enhancement at this level. Multiple mediastinal lymphadenopathies were described (Figure 2).

The chest computer tomography with contrast revealed no pulmonary parenchyma abnormalities but did describe several, non-calcified, non-necrotic hilar and mediastinal lymphadenopathies (Figure 3).

The patient was discharged after 14 days, stable, without sustained ventricular tachycardia on follow-up Holter EKG monitoring, with a recommendation for long-term treatment with Amiodarone, Metoprolol, Perindopril and Atorvastatin.

Post-discharge, another clinic performed a mediastinoscopy with lymphadenectomy on the patient. The pathological
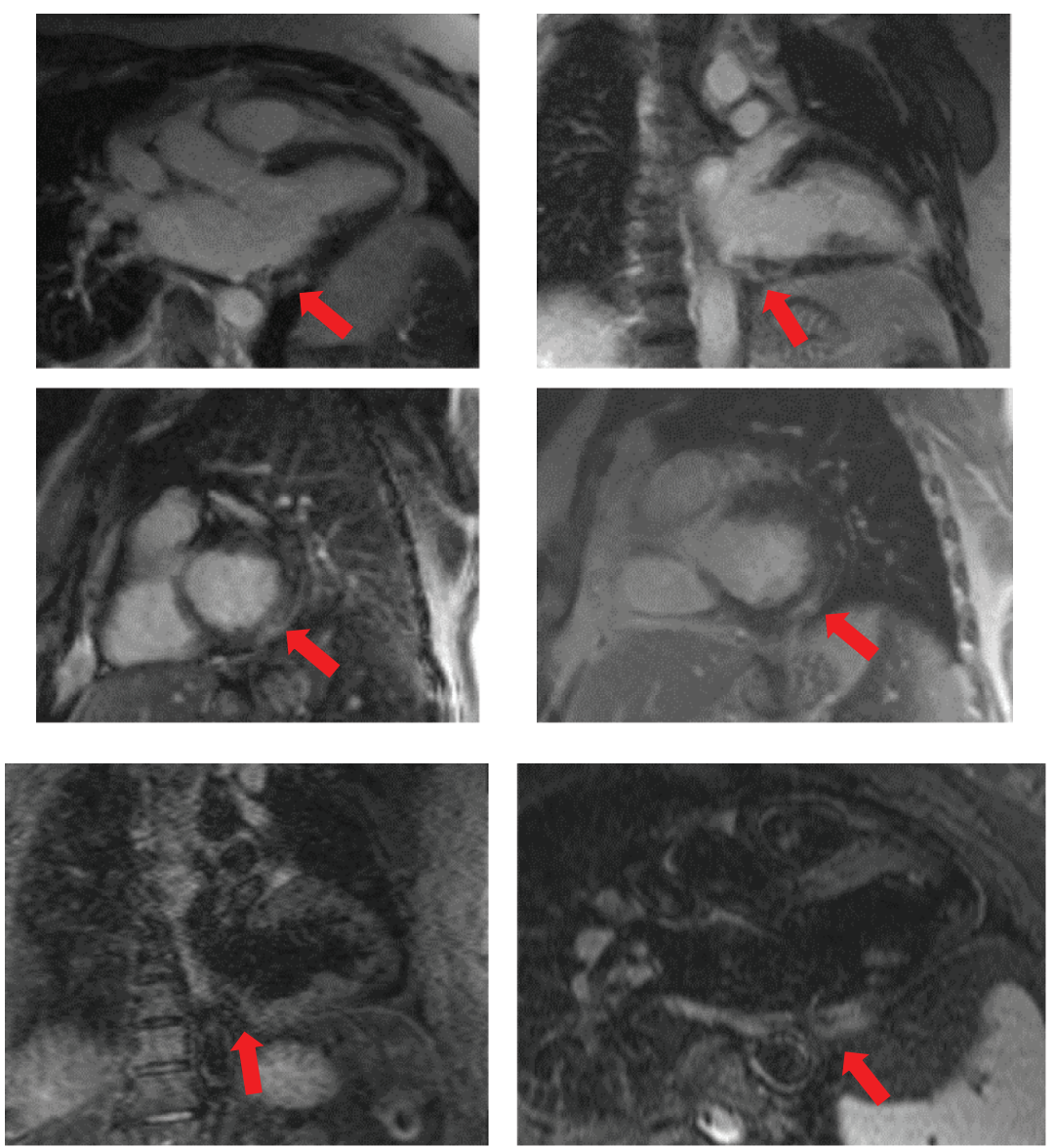

Figure 2. Cine and late gadolinium enhanced cardiac magnetic resonance sequences demonstrating fibrosis at the level of the inferolateral basal LV mid-myocardium (arrows show areas of myocardial fibrosis). LV, left ventricle. 


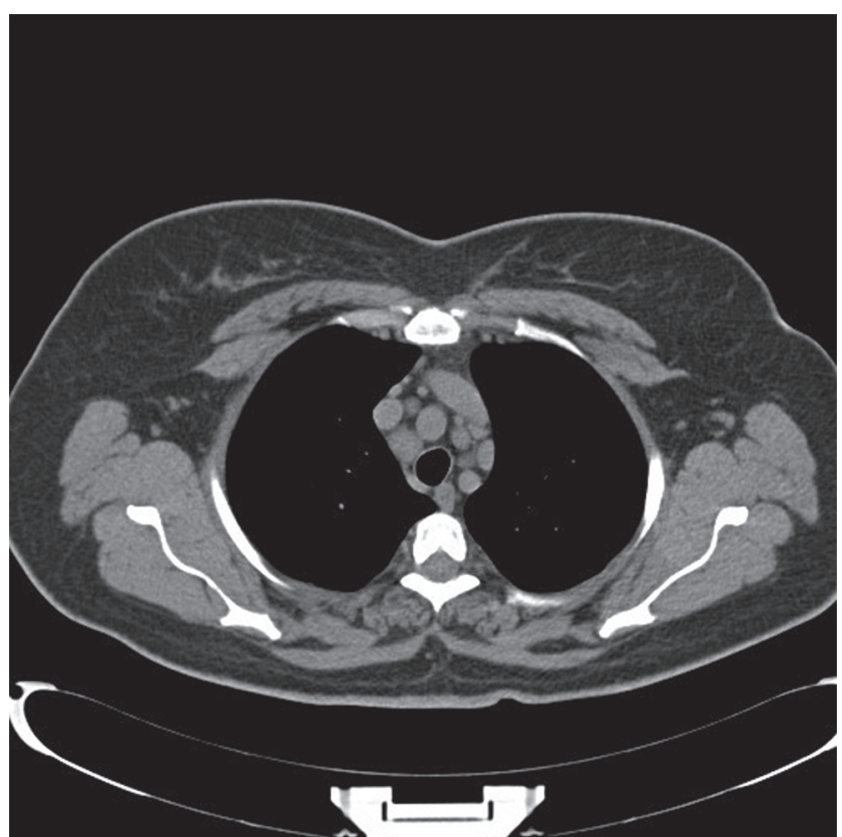

Figure 3. Native chest computed tomography (CT) transverse plane section demonstrating multiple hilar and mediastinal lymphadenopathies.

examination revealed noncaseating granulomata consistent with sarcoidosis.

Given these findings, a diagnosis of 'grade I pulmonary sarcoidosis with cardiac involvement manifested by sustained ventricular tachycardia' was established based on the following criteria: lymphadenopathy plus ventricular tachycardia unexplained by other conditions and late gadolinium enhancement on cardiac magnetic resonance in a pattern consistent with cardiac sarcoidosis. Weight-adjusted methylprednisolone $(0.5 \mathrm{mg} / \mathrm{kg})$ was added to the patient's treatment, with slow dose tapering in the following 18 months.

\section{Follow-up and evolution}

Her 3-month follow-up included a $24 \mathrm{~h}$ Holter EKG recording which revealed only two episodes of non-sustained ventricular tachycardia and isolated ventricular premature beats. A 6-month follow-up $24 \mathrm{~h}$ Holter EKG revealed only rare isolated ventricular premature beats.

The patient attended regular follow-ups for 6 years after the initial diagnosis, with a $24 \mathrm{~h}$ Holter EKG and cardiac ultrasound every 6 months and an annual chest CT scan. Methylprednisolone was stopped after 18 months and Amiodarone was discontinued after 2 years. The clinical course was favourable, the patient remained arrhythmia-free and maintained a normal left ventricular ejection fraction while the mediastinal lymphadenopathies completely regressed on control CT scans.
In 2018, the patient developed breast cancer for which she was administered surgical treatment and chemotherapy and achieved remission.

\section{Conclusion and discussion}

In cardiac sarcoidosis, the EKG and echocardiogram may show non-characteristic changes, while cardiac magnetic resonance most frequently shows a late gadolinium uptake pattern at the mid-myocardial and epicardial left ventricular levels, with relatively frequent involvement of the basal segments of the interventricular septum and lateral left ventricular wall (5).

Treatment of cardiac sarcoidosis include corticosteroids as the first line of therapy, generally $0.5 \mathrm{mg} / \mathrm{kg} /$ day prednisone for 3 months followed by a PET-CT scan to document disease activity, with an appropriate increase or tapering of doses. In refractory cases or due to serious adverse reactions, alternative treatment modalities include Methotrexate, Cyclophosphamide, Azathioprine, or Infliximab (6, 10). The first line of treatment for malignant ventricular arrhythmias in cardiac sarcoidosis also involves corticoids. If ventricular tachycardia is not controlled by steroids alone, anti-arrhythmic drugs are recommended. When these also fail, ablation therapy is indicated. Implantable cardiac defibrillators have a class I recommendation for patients with a history of cardiac arrest or sustained ventricular tachycardia, as well as for patients with a left ventricular ejection fraction $\leq 35 \%$ and presence of nonsustained ventricular tachycardia or ventricular tachycardia/ ventricular fibrillation on electrophysiological study induction $(5,7)$. Class Ila indications include patients with left ventricular dysfunction who receive immunosuppressive therapy, those with an indication for permanent pacing, with a history of syncope of unknown origin, or with delayed contrast enhancement on cardiac magnetic resonance or positive fluorodeoxyglucose positron emission tomographycomputed tomography $\left({ }^{18} \mathrm{~F}-\mathrm{FDG}\right.$ PET-CT $)$ along with the presence of electrophysiological study induced ventricular tachycardia/ventricular fibrillation or spontaneous nonsustained ventricular tachycardia (5).

In the case of our patient, the most noteworthy aspects are the atypical clinical debut of the patient's cardiac pathology, with a first episode of symptomatic sustained ventricular tachycardia unmasking significant cardiac involvement secondary to lowgrade pulmonary sarcoidosis, as well as the significant effects of corticotherapy on the patient's malignant arrhythmia. It is worth mentioning that ventricular tachycardia as the first manifestation of cardiac sarcoidosis only occurs only in $<25 \%$ of cases (5). The unavailability of PET-CT scan due to lack of expertise for myocardial protocol techniques could raise the question of whether the decision to prolong corticosteroid 
therapy longer than was actually needed to quench the inflammatory process was unnecessary and may have had a negative impact on the patient's diabetes management. Although the patient could have benefited from an implantable cardioverter defibrillator (as secondary sudden cardiac death prophylaxis), the procedure was not initially performed due to a lack of in-hospital Implantable cardioverter defibrillator (ICD) availability. Afterwards, the consulting arrhythmologist deemed it unnecessary, given the beneficial effects of corticotherapy on disease progression and arrhythmogenesis. A possible connection between sarcoidosis and an increased risk for cancer has been reported, although further studies are needed for thorough demonstration, as this may yet be a sign that carcinogenesis in sarcoidosis occurs mainly as a consequence of immune dysregulation $(8,9)$.

\section{Disclosure}

The patient's consent for publication was obtained. The authors have no conflicts of interest to declare.

\section{References}

1. Birnie D, Ha ACT, Gula LJ, Chakrabarti S, Beanlands RSB, Nery P. Cardiac sarcoidosis. Clinics in Chest Medicine. 2015;36(4): 657-668.

2. Okada DR, Bravo PE, Vita T, Agarwal V, Osborne MT, Taqueti VR, et al. Isolated cardiac sarcoidosis: A focused review of an under-recognized entity. Journal of Nuclear Cardiology. 2018;25(4): 1136-1146.

3. Birnie DH, Nery PB, Ha AC, Beanlands RSB. Cardiac sarcoidosis. Journal of the American College of Cardiology. 2016;68(4): 411-421.
4. Mills KJ, Ferrer MS, Gonzalez MD. Prominent epsilon waves in a patient with cardiac sarcoidosis. JACC Case Reports. 2020;2(4): 577-582.

5. Terasaki $F$, Azuma A, Anzai $T$, Ishizaka N, Ishida $\mathrm{Y}$, Isobe $\mathrm{M}$, et al. JCS 2016 guideline on diagnosis and treatment of cardiac sarcoidosis - digest version. Circulation Journal. 2019;83(11): 2329-2388.

6. Al-Khatib SM, Stevenson WG, Ackerman MJ, Bryant WJ, Callans DJ, Curtis AB, et al. 2017 AHA/ACC/HRS Guideline for management of patients with ventricular arrhythmias and the prevention of sudden cardiac death: A report of the American College of Cardiology/American Heart Association Task Force on Clinical Practice Guidelines and the Heart Rhythm Society. Journal of the American College of Cardiology. 2018;72(14): e91-e220.

7. Birnie DH, Sauer WH, Bogun F, Cooper JM, Culver DA Duvernoy CS, et al. HRS expert consensus statement on the diagnosis and management of arrhythmias associated with cardiac sarcoidosis. Heart Rhythm. 2014;11(7): 1304-1323.

8. Sawal N, Al Khalisy H, Mukherjee S, Habib G, Martinez-Balzano C. Cancer and sarcoidosis: an analysis of time to malignancy in sarcoidosis. Chest. 2020;158: A1178.

9. Arkema EV, Cozier YC. Epidemiology of sarcoidosis: current findings and future directions. Therapeutic Advances in Chronic Disease. 2018;9(11): 227-240.

10. Kandolin R, Lehtonen J, Airaksinen J, Vihinen T, Miettinen H, Ylitalo K, et al. Cardiac sarcoidosis: epidemiology, characteristic and outcome over 25 years in a nationwide study. Circulation. 2015;131(7): 624-632.

11. Mehta D, Lubitz SA, Frankel Z, Wisnivesky JP, Einstein AJ, Goldman M, et al. Cardiac involvement in patients with sarcoidosis: diagnostic and prognostic value of outpatient testing. Chest. 2008;133(6): 1426-1435. 